\title{
Adherence to Antiretroviral Drugs in North-Central Zone of Nigeria
}

\section{M.D. MOHAMMED ${ }^{1}$ AND R. SARKI ${ }^{2}$}

${ }^{\prime}$ M.D. Mohammed, Department of Medicine, State House Clinic, P.M. B. 316, Garki, Abuja, Nigeria.

${ }^{2}$ R. Sarki, Pharmacy Department; State House Clinic, P.M.B. 316, Garki, Abuja, Nigeria

A cross-sectional study of 110 patients attending State House Clinic, Abuja were assessed for compliance in time and dose of anti-retroviral drugs for one month. One hundred and five of the patients complied to taking the drugs (taking compliance $>95 \%$ ) and compliance to the dosage was also good $(98.1 \%)$. However, the mean timing compliance was not good $(73.1 \%)$. Forgetfulness $(7.0 \%)$ and travelling out of town (4.3\%) were the commonest reasons for missing a dose. Forgetfulness $(20 \%)$, non-availability of food $(25.5 \%)$ and stigmatization of carrying drugs around $(3.6 \%)$ were the commonest reasons for altering the dosing time. It was concluded that the timing compliance was low and that may affect the success of the program. Patients should be encouraged to take the right dose at the right time.

Keywords: Adherence, antiretroviral drugs, compliance.

\section{INTRODUCTION}

From the recent survey in Nigeria, there are about 3.5 million Nigerians living with HIV/AIDS, representing $5.0 \%$ of the population [1]. In January 2002, the Federal government of Nigeria commenced a program to provide anti-retroviral (ARV) drugs at a subsidised rate (Stavudine, Lamivudine and Nevirapine), to ten thousand people living with HIV/AIDS. As the government is planning to scale-up the program through the global-funds initiatives, getting patients to take a large amount of tablets everyday without missing any for the rest of his/her life is one of the biggest challenges.

While much success has been recorded with both good immunological and virologic responses in patients receiving ARV drugs, adherence to medication is probably the single most important factor in determining the success of ARV therapy [2]. Several studies have demonstrated that lapses in ARV adherence lower the likelihood of suppressing viremia below detectable levels. In one study, self-reported no adherence to ARV drugs was associated with a lower likelihood of suppressing plasma viral load below 50 copies $/ \mathrm{ml}$ at 52-weeks follow-up [3]. Other studies have found similar relationships between missed doses and viral load $[4,5]$.
Although previous studies in Nigeria have reported good adherence to ARV drugs among HIV/AIDS patients, none of the studies investigated the dosing time $[6,7]$. Studies elsewhere have demonstrated viral replication in the blood of patients on ARV drugs after delay of just few hours with potential of resistance development. This study therefore is aimed at assessing patient's adherence to ARV drugs by determining the taking compliance, correct dosing compliance and the timing compliance and to determine the factors that affect the taking and timing compliance.

\section{METHODOLOGY}

The study was conducted in State House Clinic, Abuja which is one of the 25 centres providing Federal Government subsidized ARV drugs to HIV/AIDS patients. There are over 350 registered patients currently receiving ARV drugs in the centre. Abuja, being the capital city of Nigeria is a cosmopolitan city with ethnic representation from all over the country. The study was a crosssectional study conducted from June 2004 to September 2004.

One hundred and ten consecutives patients were selected and after informed consent were given a drug chart at the point of drug dispensing to 
record the time and the number of drugs taken each time for one month. On returning of the chart for another one month dose, they were administered a structured questionnaire by the pharmacists. The questionnaire sought demographic information, who purchases the drugs for the patients and whether they are on other drugs. In addition, emergency hospitalization or visit to the clinic in the last one month was also recorded in addition to symptoms such as nausea, vomiting, difficulty in swallowing, painful swallowing or abdominal pain that may have affected adherence to drugs were recorded. Taking compliance (percentage of prescribed number of doses taken), correct dosing compliance (percentage of days with correct number of doses) and timing compliance (percentage of doses taken within prescribed intervals) were calculated for each patient. Those who did not meet $100 \%$ taking, timing and correct dosing compliance were asked reasons for missing dose or alteration in dosing time.

Data generated from the questionnaire were entered and analysed using Epi info 3.2.2 statistical packages.

\section{RESULTS}

A total of 110 patients were interviewed, of these $50(45.5 \%)$ were females and $60(54.5 \%)$ were mal- iic patients ranged between $14-58$ years :a mean age of $36.5 \pm 7.6$ years. Sixty-one $(55.5 \%)$ were married and $22(20.0 \%)$ were single. Widows and widowers comprised of 24 $(21.8 \%)$ while $3(2.7 \%)$ were divorced. Majority of the patients $64(58.2 \%)$ had tertiary education, while $29(26.4 \%)$ and $15(13.6 \%)$ had secondary and primary education, respectively. Majority 56 $(51.4 \%)$ of the patients were civil servants.

All the patients were on ARV drugs ranging from $1-72$ months, mean $16.9 \pm 10.7$ months. Most 78 $(75 \%)$ were purchasing their drugs themselves while $14(13.5 \%)$ and $6(5.8 \%)$ were given by their employers and spouses, respectively. The commonest symptoms reported in the last one month were abdominal pain $(19.1 \%)$, loss of appetite $(14.5 \%)$ and vomiting $(9.1 \%)$. However, none of the symptoms affected their taking of drugs.
Majority of the patients adhered to their drugs, with $105(95.5 \%)$ patients having taking compliance $\geq 95 \%$. The dosing compliance was also good, ranged $64 \%-100 \%$ (mean $98.1 \pm 5.2 \%$. However, the timing compliance was not good (range $0-100 \%$, mean $73.1 \pm 31.1 \%$ ). Reasons given for either missing dose or alteration of dosing times differed. $6.4 \%$ missed a dose due to forgetfulness and $20.9 \%$ altered the dosing time due to forgetfulness, while $3(2.7 \%)$ said they were not properly counselled. Non-availability of food was given by $28(25.5 \%)$ as a reason for altering dosing time, while stigmatization of carrying drugs around was given by $4(3.6 \%)$ and $5(4.5 \%)$ said to have travelled out of town and left the drugs behind.

Assuming adherence $\geq 95 \%$ as good adherence, neither educational qualification nor marital status or source of drugs and pills burden seem to significantly affect adherence to ARV drugs $(p>0.05)$.

\section{DISCUSSION}

Apart from directly observed therapy (DOT), there is no "gold standard" test for adherence. Several methods that have been used to assess adherence include Medication Event Monitoring System (MEMS), patient self-report (SR), antiretroviral drug levels, physician report, pill counts, pharmacy logs, and patients diary. Most studies of adherence use one or more of these tools. DOT, which has been used with success in treating tuberculosis (TB), [8]' seems less feasible in HIV disease outside trial level. First, HIVpositive patients require a lifetime of therapy, compared with 9 to 12 months of therapy for TB. Secondly, 2- and 3-times-daily regimens required for HIV are difficult and expensive to monitor compared with thrice-weekly monitoring for TB. Finally, issues of confidentiality and identification make it more difficult to mandate DOT for HIV infection as has been done for TB.

MEMS though reliable [4], is cumbersome, expensive and besides, such technology is not yet available to developing countries. Antiretroviral drug levels may be reliable, but is also affected by other factors such as drug absorption and is impracticable as lifelong tools of monitoring 
adherence [9]. So in the present circumstances, combination of self-report and patients diary (charts) is possibly the best option. Previous studies have found $S R$ to be a useful tool in measuring adherence and it is very reliable when patients report non-adherence. However it overestimates adherence by between $5-20 \%$ in those that claim adherence $[10,11]$.

The finding of $95.5 \%$ patients having taking compliance $\geq 95 \%$ represents good adherence to ARV drugs in our centre. Although, it is possible that was an overestimation as it was with other self-report studies. However, the timing compliance of $0-100 \%$ may have adverse therapeutic implications. For a patient on twicedaily medication, taking one dose at $6.00 \mathrm{a} . \mathrm{m}$ and second dose at 2.00 p.m or 12 midnight may both report good taking and dosing compliance, but that is far from being ideal because of poor timing compliance which may lead to virologic failure and possible emergence of resistance. This development is worrisome for 2 reasons. First, resistance to ARV drugs have been reported already in drug naives patients in Nigeria [12]. Secondly, in a developing country such as Nigeria, the options of second line drugs are limited.

The finding that age, sex, marital status, level of education and employment status do not significantly affect adherence is similar to other studies elsewhere $[13,14]$ Although psychosocial factors were found to be predictive of nonadherence, these were not tested in this study [14]. Some studies in Nigeria have found source of drugs whether self-purchased or free drugs to affect adherence $[6,7]$. This was not so with this study, partly because, it assessed compliance over one month and all patients received their supply of ARV drugs for one month irrespective of source. Pills burden and side effects also do not seem to affect adherence significantly in this study partly because no serious side effects were reported during the period of the study. Other studies elsewhere also did not find pills burden to significantly affect adherence $[15,16]$.

Forgetfulness was the main reason given for missing medication and this was the finding with many other studies $[17,18]$. Furthermore, forgetfulness and non-availability of food were the commonest reasons for altering dosing time. The latter has highlighted the necessity of proper counselling to the patients, since the regimen used did not include a protease inhibitor, which normally has relationship with food intake. The facts that up to $25.5 \%$ reported non-availability of food as a reason for delaying or altering dosing time means we have to educate the patients more. Although only $3.6 \%$ of respondent gave stigmatization as reason, it is still a problem as most patients will not like to carry their drugs to work or public outing for fear of stigmatization and that may lead to altering dosing time.

In conclusion, in order to maximise the benefit of ARV therapy, which the Global Fund for HIV/AIDS, malaria and tuberculosis and other initiatives are trying to provide, we have to encourage and educate our patients to adhere more not just the need to take the drugs, but also taking the right dose at the right time.

\section{ACKNOWLEDGEMENT}

We wish to acknowledge Dr. I. Dalhatu and Dr. A. Mohammed for their constructive criticisms.

\section{REFERENCES}

[1] Situation of ARV DRUG USE IN NIGERIA. Published by The Federal Ministry of Health in Collaboration with The World Health Organisation, (2003).

[2] E.O. Idigbe, T. Adewole and G. Esien. $13^{\text {th }}$ International Conference on AIDS and STI in Africa. $21^{\text {st }}-26^{\text {th }}$ September 2003. Abstract no. 328-12-KEO3-2.

[3] J.S. Montaner, P. Reiss and D. Cooper et al. JAMA. 279 (1998) 930-937.

[4] D. Paterson, S. Swindles and J. Mohr. Proceedings of the $6^{\text {th }}$ Conference on Retroviruses and Opportunistic Infections; January 31-February 4, 1999 Chicago. Abstract 92.

[5] H. Knobel, A. Carmona, S. Grau, et al. Arch Intern Med. 158 (1998) 1953-1956. 
[6] O.J. Daniel, S.A. Ogun, O.L. Odusoga, F.A. Oluwole Proceedings of the $4^{\text {th }}$ National Conference on HIV/AIDS in Nigeria; May $2-5^{\text {th }}$ 2004. Abstract No. Al72.

[7] E. Ekong, C. Idehen, O. Idigbe and A. Uwah. Proceedings of the $4^{\text {th }}$ National Conference on HIV/AIDS in Nigeria; May 2-5 2004. Abstract No. A306.

[8] C.P. Chaulk and M.D. Iseman. Lancet. 350 (1997) 666.

[9] A. Tuldra, J.M. Ferrer, C.R. Fumaz et al. Arch Intern Med. 159 (1999) 1376-1377.

[10] J. Arnsten, P. Demas, M. Gourevitch, et al. Proceedings of the 7th Conference on Retroviruses and Opportunistic Infections; January 30-February 2, 2000; San Francisco. Abstract 69.

[11] K.M. Melbourne, S.M. Geletko, S.L. Brown, et al. AIDS Reader. 9 (1999) 329-338.
[12] Agwale Simon, L. Tanimoto, C. Womack, M. Sawa, I. Audu and L. Odama. $4^{\text {th }}$ National Conference on HIV/AIDS in Nigeria; May $2-5^{\text {th }}$ 2004. Abstracts No. A548.

[13] R.H. Haubrich, S.J. Little and J.S. Currier, et al. AIDS. 13 (1999) 1099-1107.

[14] C.L. Besch . Compliance in clinical trials. AIDS. 9 (1995) 1-10.

[15] N. Singh, C. Squier, C. Sivek, et al. A IDS Care. 8 (1996) 261-269.

[16] N. Singh, S.M. Berman, S. Swindles, et al. Clin Infect Dis. 29 (1999) 824-830.

[17] J.H. Samet, H. Libman and K.A. Steger, et al. Am J Med. 92 (1992) 495-502.

[18] R. Bayer, C. Stayton, M. Desvarieux, et al. Am J Public Health. 88 (1998) 10521058. 